\title{
Supratentorial neurenteric cyst mimicking hydatid cyst: A case report and literature review
}

\author{
Mohammad Arabi, Mohannad Ibrahim, Sandra Camelo-Piragua' ${ }^{1}$, Gaurang Shah \\ Departments of Radiology and ${ }^{1}$ Pathology, University of Michigan Health System, Ann Arbor, MI, USA
}

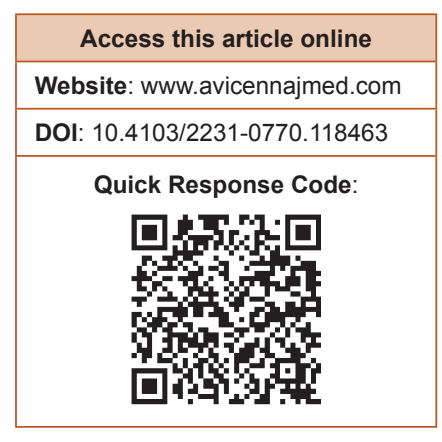

\section{ABSTRACT}

Neurenteric (NE) cysts are uncommon congenital cysts of endodermal origin. These cysts are commonly encountered in the posterior fossa surrounding the brain stem structures. We present a case of pathologically proven supratentorial NE cyst that mimicked a hydatid cyst in its clinical presentation and imaging appearance. Including this pathology in the differential diagnosis of supratentorial cystic lesions is important due to the differences in medical and surgical management.

Key words: Hydatid, neurenteric cyst, supratentorial

\section{INTRODUCTION}

Central nervous system (CNS) neurenteric (NE) cysts are uncommon congenital cysts that originate from the endoderm. ${ }^{[1]}$ The majority of NE cysts is encountered in the spine and is reportedly associated with vertebral anomalies in approximately $50 \% \cdot{ }^{[1]}$ Conversely, Intracranial NE cysts are rare and typically located in the posterior fossa anterior to the mid brain structures. Supratentorial NE cysts have been rarely reported and tend to be larger in size compared with their posterior fossa counterparts. ${ }^{[1]}$ The present case emphasizes the importance of including NE cysts in the differential diagnosis of more common supratentorial cystic lesions as this may alter the management approach.

\section{CASE REPORT}

A 67-year-old Mediterranean male who had episodes of seizures with altered consciousness. He was subsequently placed on keppra and became seizure-free. Magnetic resonance imaging (MRI) of the brain with and without gadolinium revealed a large well-defined left frontal cystic mass measuring $4.8 \mathrm{~cm} \times 4.0 \mathrm{~cm} \times 4.8 \mathrm{~cm}$. The mass displays cerebrospinal fluid (CSF) intensity with low signal on T1-weighted and fluid-attenuated inversion recovery (FLAIR) images [Figure 1] and high signal on T2-weighted (T2W) images [Figure 2]. The lesion contained sausage-shaped debris of high FLAIR signal in its dependent portion with an internal septation. On post contrast imaging, there is no discernible enhancement of the mass or any surrounding capsule. The diffusion tensor imaging (DTI) and diffusion weighted imaging exhibits presence of a high T2 signal wall surrounded by a low signal capsule. On the functional MRI, the left-sided primary motor cortex is seen along the posterior and lateral margin of the left frontal cyst [Figure 3]. The activated supplemental motor area is seen along the medial margin of the cyst. The DTI revealed that

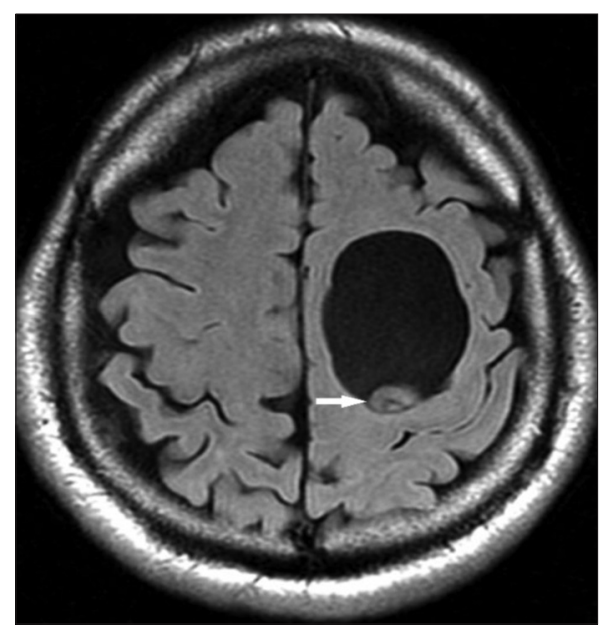

Figure 1: Axial fluid-attenuated inversion recovery image shows a well-defined left frontal low signal cystic lesion with high signal debris in the dependent portion. There is no surrounding vasogenic edema or significant mass effect 


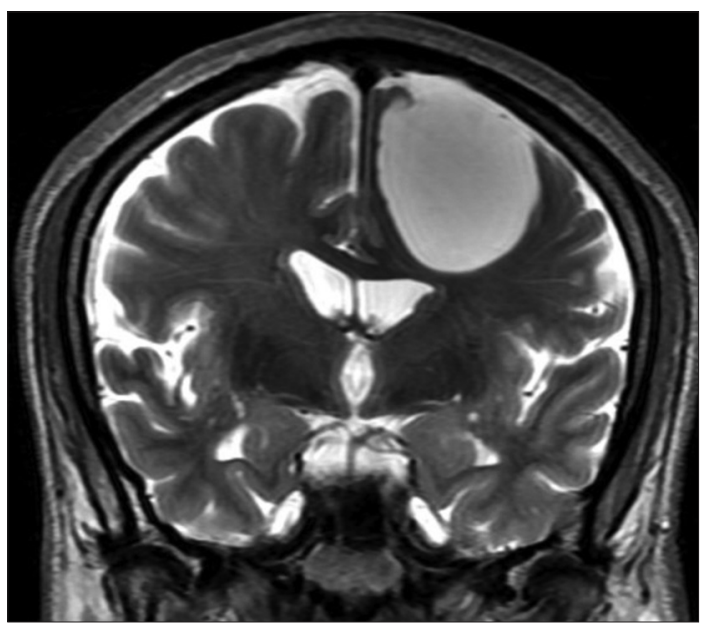

Figure 2: Coronal T2-weighted image shows the hyperintense left frontal cystic lesion significantly displacing the underlying parenchyma

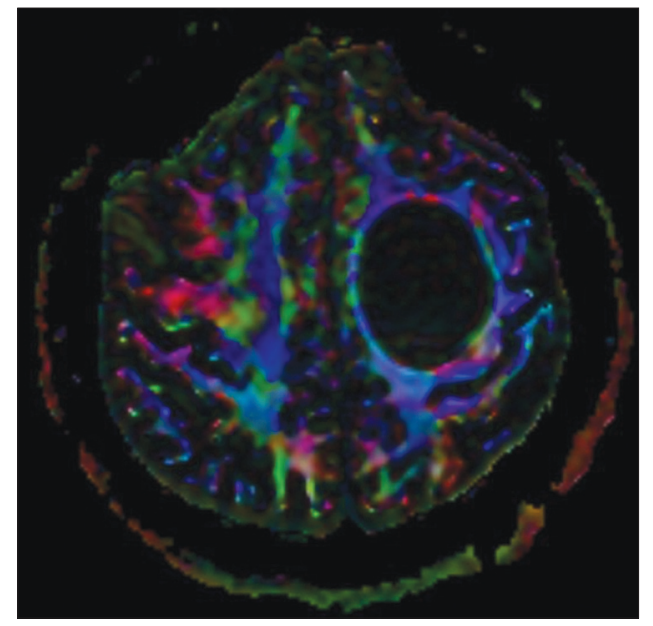

Figure 4: Axial tractography image at the level of the left frontal lesion shows cleavage of the white matter tracts by the lesion rather than infiltration or destruction

the white matter tracks of centrum semiovale are cleaved and displaced rather than infiltrated and destroyed [Figure 4]. The patient also underwent a computed tomography (CT) scan of the thorax and abdomen, as part of the patient's workup for suspected hydatid cyst disease, which revealed a mesenteric cystic lesion.

Based on the pre-operative imaging findings, the patient was started on albendazole for treatment of the presumed hydatid cyst.

Later, the patient underwent a stealth-guided left frontoparietal craniotomy for resection of cyst. The lesion was adherent to the cerebral pial surface and contained proteinaceous gelatinous yellowish discolored material. The lesion was irrigated several times with hypertonic saline to kill any hydatid ova. The patient's post-operative course was uncomplicated and albendazole was resumed. Histologically, the lesion showed a fibrous cyst wall lined

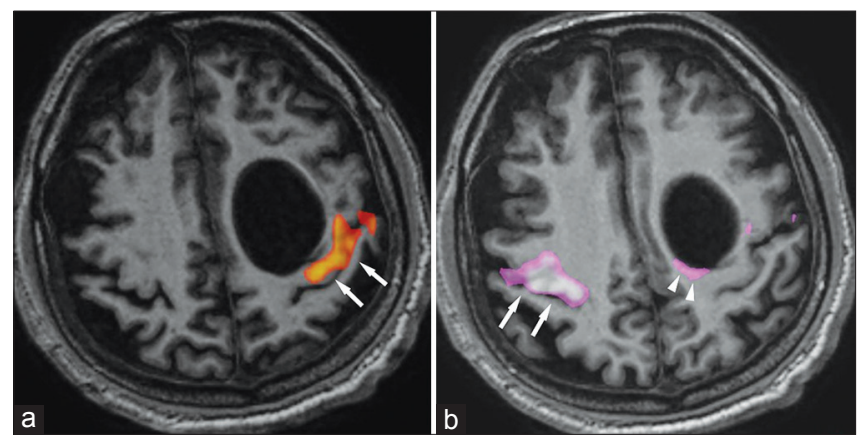

Figure 3: (a) Axial T1-weighted image overlay with a functional magnetic resonance imaging (fMRI) during the right finger tapping task demonstrates activation of the primary motor cortex (arrows) posterolateral to the cystic lesion. (b) fMRI overly image during left finger tapping task shows activation of the right primary motor cortex (arrows) and the left supplemental motor area along the medial margin of the cyst

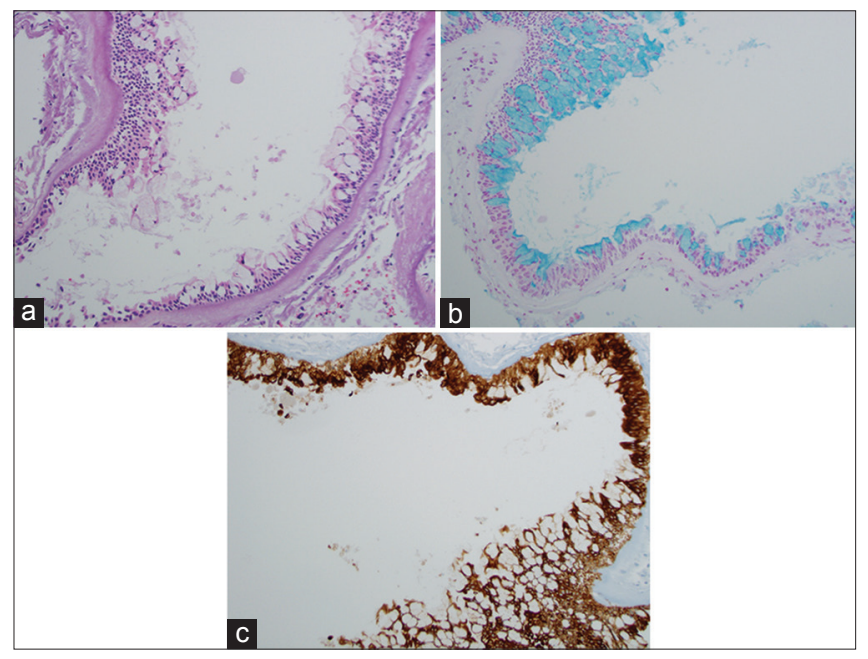

Figure 5: Histopathology of the cyst. (a) $\mathrm{H}$ and $\mathrm{E}$ stain shows a cystic lesion, with a fibrous wall, lined by pseudostratified columnar epithelium. Note that some cells harbor large intracytoplasmic mucinous contents. (b) Alcian blue staining highlights the mucin content of some cells in blue. (c) Immunohistochemical stain for pan-cytokeratin demonstrates the epithelial origin of the cyst

by cuboidal to columnar, single to multilayered epithelium, which focally shows surface cilia and mucin production that is positive on alcian blue special histochemical stain. The cystic lining is immunoreactive for pan-cytokeratin and epithelial membrane antigen (EMA) and negative for glial fibrillary acidic protein (GFAP) and CK20 [Figure 5]. The histological features are consistent with an enterogenous/ epithelial cyst. There is no evidence of hydatid cyst, scolex or other abnormal parasitic structure. Based on the final pathologic diagnosis, albendazole was discontinued.

\section{DISCUSSION}

CNS NE cysts are uncommon congenital cysts most commonly encountered in the spinal cord as intradural extramedullary cysts. They are generally, situated ventral to the spinal cord and are most commonly seen in the lower cervical and upper thoracic regions. These cysts 
are believed to originate from the endoderm during early embryonic life. ${ }^{[1,2]}$ Several theories have been proposed to explain the pathogenesis of neurenteric cysts. Failure of separation between the notochord and the foregut that leads to incorporation of primitive endodermal cells in the notochord was proposed. However, this mechanism does not explain the existence of supratentorial cysts as the most rostral extent of the endoderm is at the level of the clivus. ${ }^{[3]}$ The "Seessel's pouch origin" hypothesis suggest a common origin for suprasellar neurenteric cysts, Rathke's cleft cysts and colloid cysts. This theory fails to explain the laterally positioned supratentorial cyst. On the other hand, Mittal et al. propose that anomalous endodermal cell migration occurs dorsally through the primitive neurenteric canal into the ectoderm and can travel cephalad and to more lateral positions. This progress explains the decreasing incidence of NE cysts from the spine toward the infra and supratentorial compartments, respectively. ${ }^{[2]}$ Given the endodermal origin of NE cysts, elements of bronchial or gastrointestinal epithelium may be seen in these cystic lesions. Furthermore, NE cysts can also contain elements derived from mesoderm and ectoderm. ${ }^{[2]}$ This complex histopathology lead to the use of several names that can be interchangeably used with NE cysts including endodermal, enteric, enterogenous, respiratory, gastroenterogenous and archenteric cysts and have also been labeled as gastrocytomas or intestinomas. ${ }^{[2,4]}$

In our review of literature, using the keywords, NE, enterogenous, endodermal and supratentorial cysts, we identified around 30 reported cases [Table 1]. The male to female ratio is $1.3: 1$ with age range between prenatal and 78 years. Clinically, supratentorial NE cysts present with symptoms of space occupying lesion depending on their location such as headache, visual changes, insomnia, seizures, mental and personality changes.

Supratentorial NE cysts are reported to be larger in size than those in the posterior fossa. Supratentorial locations include supra or parasellar, ${ }^{[9,14]}$ septum pellucidum, ${ }^{[25]}$ third ventricle, ${ }^{[7]}$ anterior fossa ${ }^{[4,13,14,16,26]}$ and along the optic nerve. ${ }^{[6]}$ The majority of supratentorial NE cysts occur in extra axial location with no definite laterality predilection. However, there are few reports of intraparenchymal NE cysts in the frontal ${ }^{[3,5]}$ and temporal lobes. ${ }^{[21]}$ All the previously reported and pathologically proven cases of supratentorial NE cysts are solitary. Walls et al. reported a case of multiple intracranial enterogenous cysts in which they presumed that the supratentorial intraparenchymal cysts are of similar pathology to the infratentorial cystic lesions. ${ }^{[5]}$ In general, NE cysts are well-defined, smooth and thin-walled, round or lobulated and rarely demonstrate marginal calcifications.
The signal characteristics of NE cysts vary depending on the protein content of the cysts. The majority of NE cysts is proteinaceous and exhibit iso to increased T1-weighted signal compared with the CSF. On T2W sequence, most of the cysts show increased signal and the remaining are hypointense. On the other hand, NE cysts can be hyperintense on FLAIR images and may show mildly impeded diffusion. Although rim of enhancement is rarely seen, Preece et al. described this finding in approximately $35 \%$ with no definitive correlation between chronic inflammatory changes/cyst rupture and rim enhancement. ${ }^{[1]}$

Complete surgical excision of supratentorial NE cysts is considered the treatment of choice. This has been achieved in most of the reported cases as the cyst could be easily dissected form the surrounding meninges and brain parenchyma. Incomplete resection or cyst fenestration may result in cyst recurrence ${ }^{[22]}$ or seeding of the cyst contents into the arachnoid space. ${ }^{[27]}$

Histologically, NE cysts are classified by Wilkins and Odom's into three categories. ${ }^{[28]}$ All types share the presence of single layer of pseudostratified columnar or cuboidal cells mimicking respiratory or gastrointestinal epithelium. Type B exhibits complex invaginations with glandular organization; mucinous or serous production; nerve ganglion, lymphoid, skeletal muscle, smooth muscle, fat, cartilage and/or bone elements. Cysts with ependymal or glial tissue are classified as Type C. ${ }^{[22]}$

The coexistence of supratentorial NE cyst and intraparenchymal subependymoma has been described. ${ }^{[22]}$ Mucinous low-grade adenocarcinoma was reported to arise from an infratentorial NE cyst. ${ }^{[29]}$ Furthermore, malignant transformation was seen in supratentorial NE cysts into invasive mucinous papillary cystadenocarcinoma ${ }^{[19]}$ and well-differentiated papillary adenocarcinoma. ${ }^{[8]}$

In contrast to NE cysts, intracranial hydatid cysts are rare acquired cystic lesions secondary to Echinococcus granulosus infection encountered in $2 \%$ of cases. ${ }^{[30,31]}$ The most common location of CNS hydatid cysts is in the parenchymal territory of the middle cerebral artery and less commonly in the subarachnoid space. ${ }^{[31]}$ The lesions are usually well-defined, spherical, thin and smooth-walled with no peripheral calcifications or enhancement. The cyst contents follow the appearance of CSF on both MR and CT. MRI, particularly T2W, can be better in depicting the wall due to the increased contrast between the cyst contents and the hypointense wall. Hydatid cysts are rarely multiple secondary to hematogenous spread or when complicated by traumatic or intraoperative rupture. 


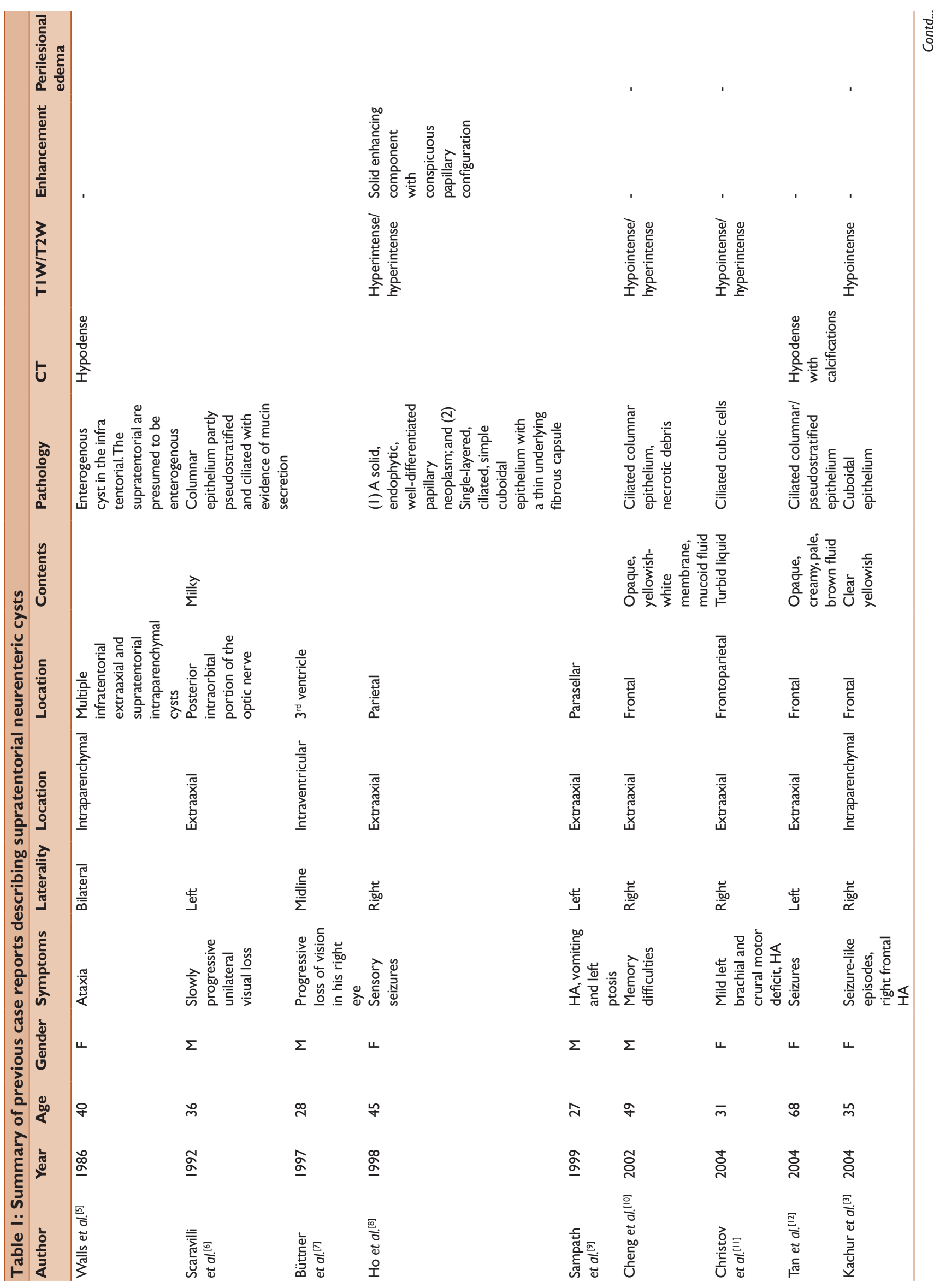





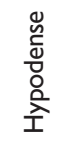

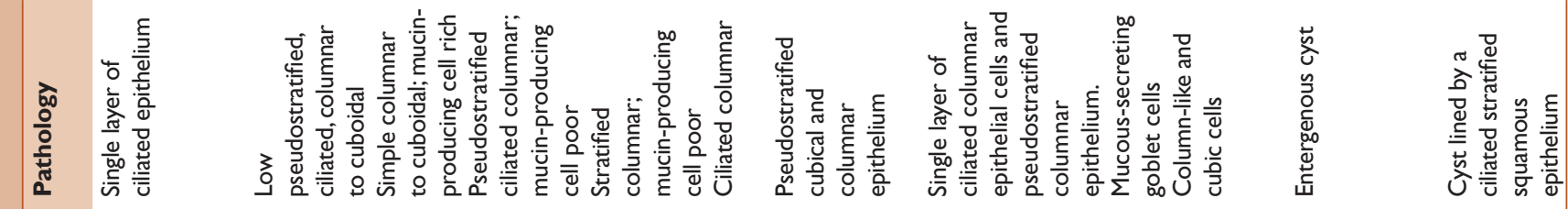

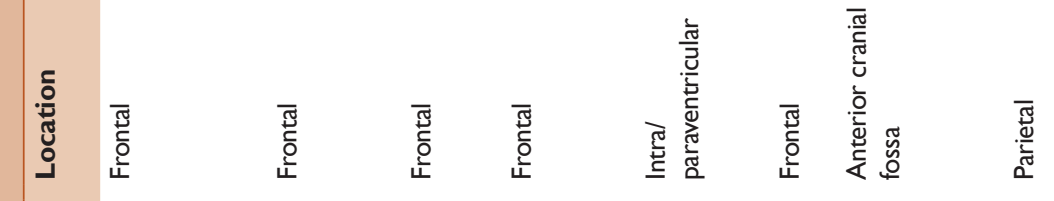

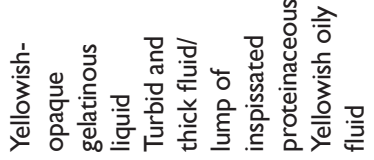

II

1

高

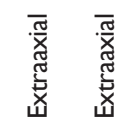



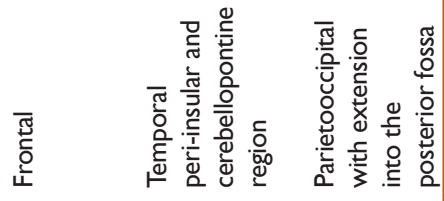

袍

$\frac{1}{40}$

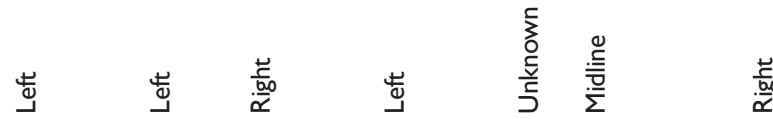

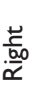

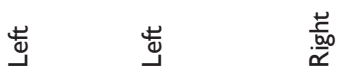

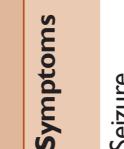

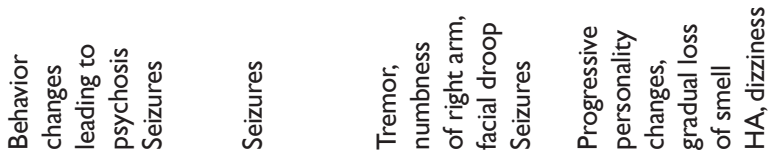

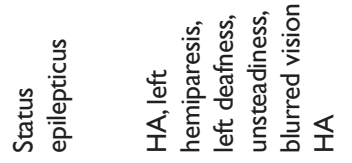

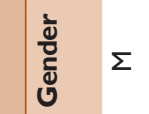

$\leftarrow$

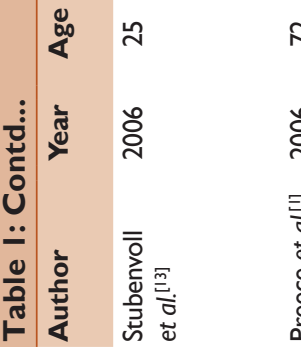

N

¿ั่

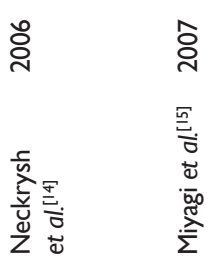

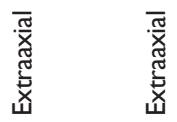

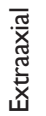

๕ั

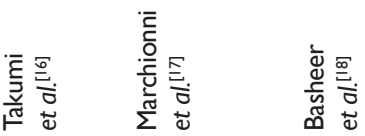


Arabi, et al.: Supratentorial neuroenteric cyst

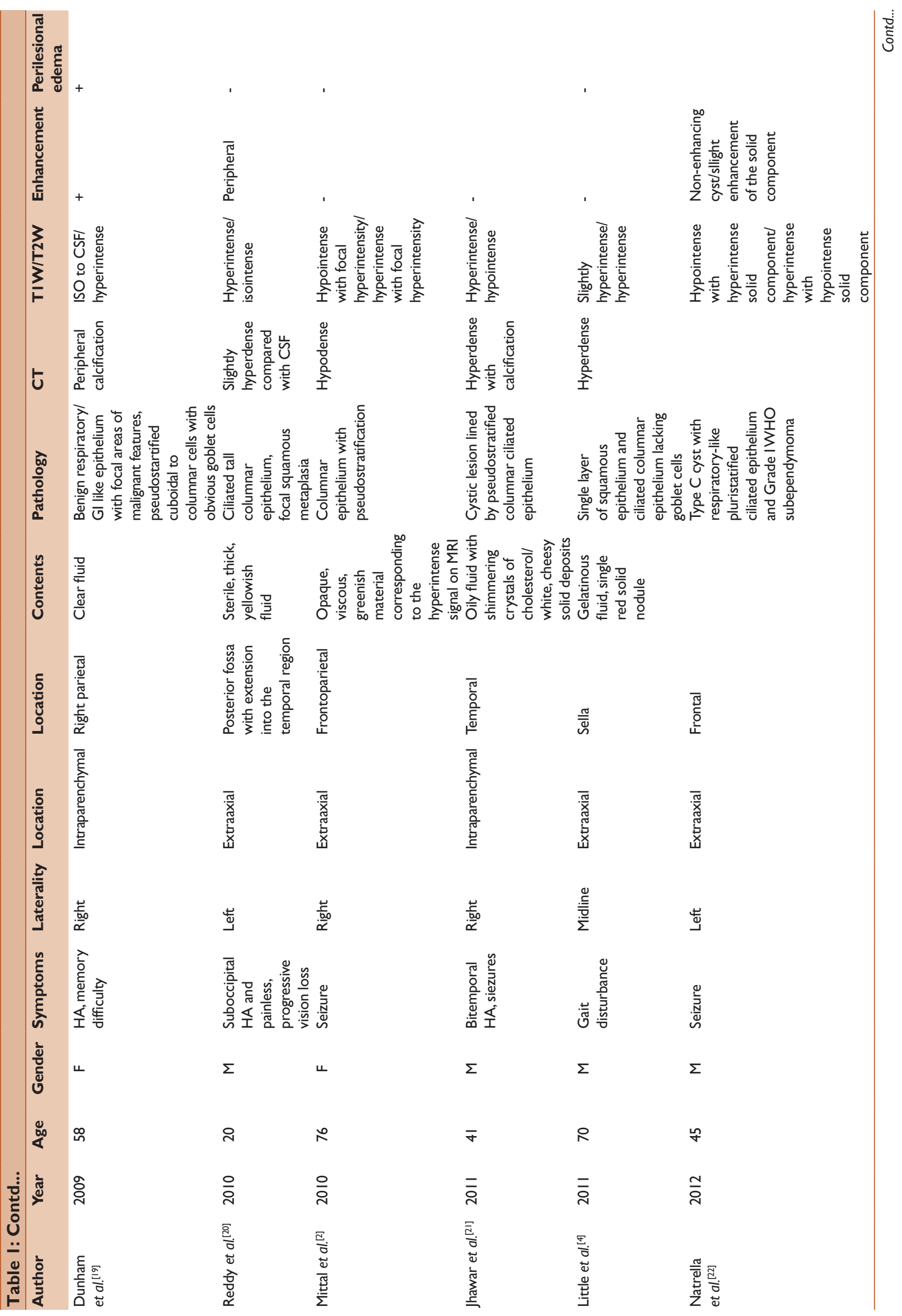




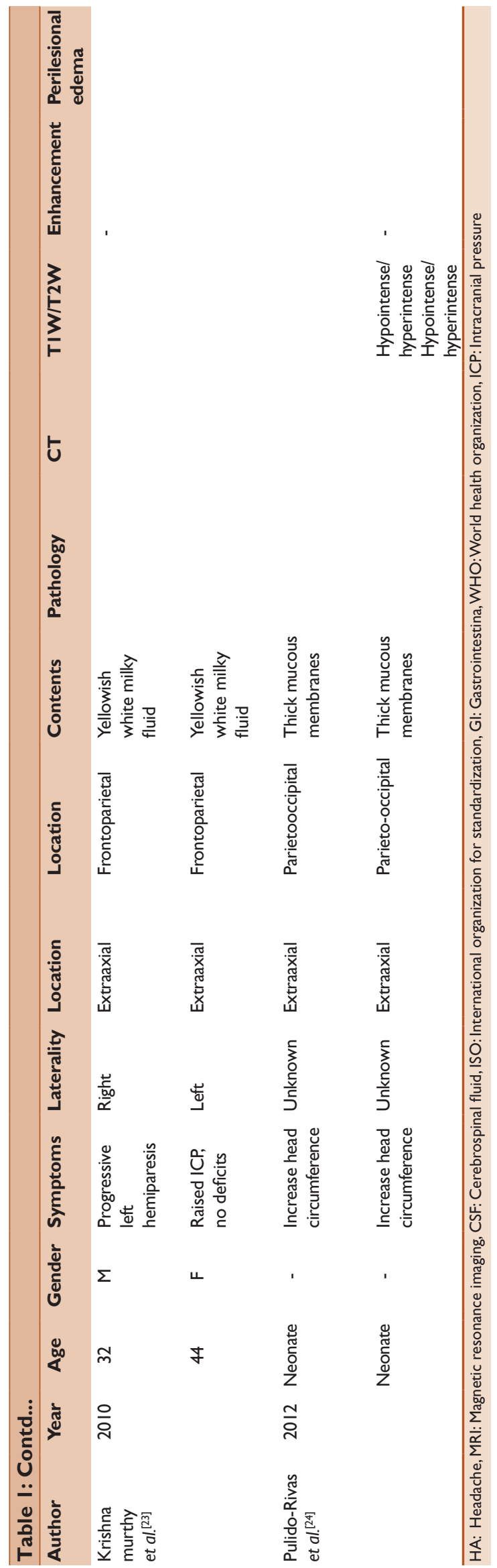

Although some intracranial cystic lesions may have distinct imaging features, the differentiation between NE cysts, hydatid cysts and other benign and malignant cystic lesions can be difficult on imaging due to the similarity in imaging features. In our case, the presence of debris within the cyst, the location and appearance of the lesion as well as the presence of mesenteric cyst initially suggested the diagnosis of hydatid cyst, which was the presumed pre-operative diagnosis. This case illustrates the similarity of imaging features between hydatid and supratentorial NE cysts that require a different management approach.

\section{REFERENCES}

1. Preece MT, Osborn AG, Chin SS, Smirniotopoulos JG. Intracranial neurenteric cysts: Imaging and pathology spectrum. AJNR Am J Neuroradiol 2006;27:1211-6.

2. Mittal S, Petrecca K, Sabbagh AJ, Rayes M, Melançon D, Guiot MC, et al. Supratentorial neurenteric cysts-A fascinating entity of uncertain embryopathogenesis. Clin Neurol Neurosurg 2010;112:89-97.

3. Kachur E, Ang LC, Megyesi JF. Intraparenchymal supratentorial neurenteric cyst. Can J Neurol Sci 2004;31:412-6.

4. Little MW, Guilfoyle MR, Bulters DO, Scoffings DJ, O’Donovan DG, Kirkpatrick PJ. Neurenteric cyst of the anterior cranial fossa: Case report and literature review. Acta Neurochir (Wien) 2011;153:1519-25.

5. Walls TJ, Purohit DP, Aji WS, Schofield IS, Barwick DD. Multiple intracranial enterogenous cysts. J Neurol Neurosurg Psychiatry 1986;49:438-41.

6. Scaravilli F, Lidov H, Spalton DJ, Symon L. Neuroenteric cyst of the optic nerve: Case report with immunohistochemical study. J Neurol Neurosurg Psychiatry 1992;55:1197-9.

7. Büttner A, Winkler PA, Weis S. Endodermal cyst of the third ventricle: Case report. Neurosurgery 1997;40:832-5.

8. Ho LC, Olivi A, Cho CH, Burger PC, Simeone F, Tihan T. Well-differentiated papillary adenocarcinoma arising in a supratentorial enterogenous cyst: Case report. Neurosurgery 1998;43:1474-7.

9. Sampath S, Yasha TC, Shetty S, Chandramouli BA. Parasellar neurenteric cyst: Unusual site and histology: Case report Neurosurgery 1999;44:1335-7.

10. Cheng JS, Cusick JF, Ho KC, Ulmer JL. Lateral supratentorial endodermal cyst: Case report and review of literature. Neurosurgery 2002;51:493-9.

11. Christov C, Chrétien F, Brugieres P, Djindjian M. Giant supratentorial enterogenous cyst: Report of a case, literature review, and discussion of pathogenesis. Neurosurgery 2004;54:759-63.

12. Tan GS, Hortobágyi T, Al-Sarraj S, Connor SE. Intracranial laterally based supratentorial neurenteric cyst. Br J Radiol 2004;77:963-5.

13. Stubenvoll F, Beschorner R, Danz S, Freudenstein D. Fronto-laterally located supratentorial bronchogenic cyst: Case report and review of the literature. Clin Neuropathol 2006;25:123-7.

14. Neckrysh S, Valyi-Nagy T, Charbel FT. Neuroenteric cyst of the anterior cranial fossa: Case report and review of the literature. Surg Neurol 2006;65:174-7.

15. Miyagi A, Katayama Y. Neurenteric cyst arising in the high convexity parietal lesion: Case report. Neurosurgery 2007;60:E203-4.

16. Takumi I, Mori O, Mizutani N, Akimoto M, Kobayashi S, Teramoto A. Expansile neurenteric cyst arising in the frontal lobe associated with status epilepticus: Report of a case and discussion of epileptogenesis. Brain Tumor Pathol 2008;25:97-101.

17. Marchionni M, Smith C, Eljamel MS. Intracranial enterogenous cyst extending into both supratentorial and infratentorial compartments: Case report and review of the literature. Skull Base 2008;18:213-6.

18. Basheer N, Kasliwal MK, Suri A, Sharma MC, Arora A, Sharma BS. 
Lateral extradural, supratentorial neurenteric cyst. J Clin Neurosci 2010;17:639-41.

19. Dunham CP, Curry B, Hamilton M. Malignant transformation of an intraaxial-supratentorial neurenteric cyst-case report and review of the literature. Clin Neuropathol 2009;28:460-6.

20. Reddy RS, Vijayasaradhi M, Uppin MS, Challa S. A rare case of extradural neurenteric cyst with supratentorial and infratentorial extension. Acta Neurochir (Wien) 2010;152:1957-9.

21. Jhawar SS, Nadkarni T, Goel A. Intraparenchymal temporal neurenteric cyst. J Clin Neurosci 2011;18:415-7.

22. Natrella F, Mariottini A, Rocchi R, Miracco C. Supratentorial neurenteric cyst associated with a intraparenchymal subependymoma. BMJ Case Rep 2012;2012.

23. Krishnamurthy G, Roopesh Kumar VR, Rajeswaran R, Rao S. Supratentorial enterogenous cyst: A report of two cases and review of literature. Neurol India 2010;58:774-7.

24. Pulido-Rivas P, López-García A, Jiménez-Heffernan J, Sola RG. Intracerebral neurenteric cysts in newborn infants. Rev Neurol 2012;55:26-30.

25. Mishra GP, Sharma RR, Musa MM, Pawar SJ. Endodermal cyst of septum pellucidum and pregnancy: A case report. Surg Neurol 2000;53:583-5.
26. Bavetta S, El-Shunnar K, Hamlyn PJ. Neurenteric cyst of the anterior cranial fossa. Br J Neurosurg 1996;10:225-7.

27. Perry A, Scheithauer BW, Zaias BW, Minassian HV. Aggressive enterogenous cyst with extensive craniospinal spread: Case report. Neurosurgery 1999;44:401-4.

28. Wilkens RH, Odom GL. Spinal intradural cysts. In: Vinkin PJ, Bruyn GW, editors. Tumors of the Spine and Spinal Cord, Handbook of Clinical Neurology. Vol. 20. Part II. 1976. p. 55-102.

29. Gessi M, Legnani FG, Maderna E, Casali C, Solero CL, Pollo B, et al. Mucinous low-grade adenocarcinoma arising in an intracranial enterogenous cyst: Case report. Neurosurgery 2008;62:E972-3.

30. Tüzün M, Hekimoğlu B. Hydatid disease of the CNS: Imaging features. AJR Am J Roentgenol 1998;171:1497-500.

31. Osborn AG, Preece MT. Intracranial cysts: Radiologic-pathologic correlation and imaging approach. Radiology 2006;239:650-64.

Cite this article as: Arabi M, Ibrahim M, Camelo-Piragua S, Shah G. Supratentorial neurenteric cyst mimicking hydatid cyst: A case report and literature review. Avicenna J Med 2013;3:73-80.

Source of Support: Nil, Conflict of Interest: None declared.

Announcement

\section{Android App}

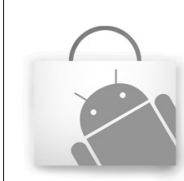

Download

Android application
A free application to browse and search the journal's content is now available for Android based mobiles and devices. The application provides "Table of Contents" of the latest issues, which are stored on the device for future offline browsing. Internet connection is required to access the back issues and search facility. The application is compatible with all the versions of Android. The application can be downloaded from https://market.android.com/details?id=comm.app. medknow. For suggestions and comments do write back to us. 